\title{
Predictors of malnutrition among elderly people above 65 Years in East Ethiopia: Neglected public health concern
}

\author{
Abdu Oumer Abdu (D Phnabu@gmail.com ) \\ Wolkite University \\ Imam Dagne \\ Dire Dawa University \\ Ahmed Ali \\ Dire Dawa University
}

\section{Research}

Keywords: malnutrition; elderly; mini nutritional assessment; Ethiopia

Posted Date: August 5th, 2020

DOI: https://doi.org/10.21203/rs.3.rs-51111/v1

License: (c) (i) This work is licensed under a Creative Commons Attribution 4.0 International License.

Read Full License 


\section{Abstract}

Background A nutritional problem, especially under nutrition is one of the common public health problems in elderly causing greater mortality and economic loss in developing countries. However, evidences on the risk factors for increased nutritional risk among elderly is not well stated in Ethiopia. This study aimed to assess the nutritional status and predictors of malnutrition among elderly $(>=65$ years) in Eastern Ethiopia.

Methods Community based survey was conducted among randomly selected 592 elderly age above 65 years of age in Harari region selected using multistage sampling Pretested full Mini Nutritional Assessment (MNA) tool was used to classify as malnourished (MNA score $<17$ ), at risk of malnutrition (MNA score of 17 to 23.5) and otherwise normal. Validated geriatric depression scale short form (15 items) was employed to screen for depression. Statistical tables, frequency, percentage and graphs. Ordinary logistic regression was employed to identify predictors of malnutrition and plum method was used to generate odds ratio. Level of statistical significance was declared at $P$ value less than $5 \%$. Chisquare test, crude and adjusted odds ratio with $95 \%$ confidence was reported.

Results A total of 592 respondents with response rate of $93.4 \%$ were interviewed. A total of $306(51.7 \%)$ and $93(15.7 \%)$ were found to be at risk of malnutrition and malnourished respectively. The predicted log odds of being malnourished was higher among those from rural residents ( $A O R=2.08: 1.25-3.45$ ), not on working $(A O R=1.31: 95 \% \mathrm{Cl}$ : 0.87-1.95) and did not have health insurance $(\mathrm{AOR}=1.58 ; 95 \% \mathrm{Cl} ; 0.97$ 2.58). Those with chronic pain ( $A O R=1.70 ; 95 \% \mathrm{Cl}: 1.15-2.51)$, previous hospitalization $(A O R=1.59$ : 95\% Cl: 1.27-2.38) and not able to cover their personal expense (AOR $=1.61: 95 \% \mathrm{Cl}: 1.12-2.30$ ) were predictors of malnutrition. The relationship between previous hospitalizations with malnutrition among elderly is moderated significantly by the presence of chronic pain $(\beta=0.113, p=0.015)$.

Conclusions Malnutrition among old age is public health concern that needs attention. Economic vulnerability, residence, depression, presence of chronic disease and hospitalization were an important risk factors for malnutrition among old age.

\section{Background}

Owning to demographic transition and advance in medical technologies, the world population structure is changing. Worldwide as of 2015 there are 617.1 million older peoples above 65 years with almost $7.6 \%$ of world Population [1]. In Africa, for example the life expectancy has risen to about 65years and account for $3.5 \%$ (40million) in 2015 [2]. While, in Ethiopia, 3.2\% of the population is older than 65 years [3].

Global health issues for older age include nutritional problems, chronic non-communicable diseases like heart disease, stroke and others. A nutritional problem, especially under nutrition is one of the common public health problems in elderly causing greater mortality and economic loss in developing countries [4]. Early detection of malnourished and at risk for malnutrition will be valuable in targeting public health interventions among elderly. 
Mini Nutritional assessment (MNA) is an important validated tool used to assess elderly who are malnourished and at risk of malnutrition. It will be administered in MNA short form (MNA SF) or the full length screening tools (18 items) [5]. But, both has validated for use. It helps to identify malnutrition early before severe malnutrition with protein depletion happens. It has higher sensitivity than Malnutrition Universal Screening Tools in identification of malnourished ones [6].

Nowadays due numerous social structural changes this segment of the population is being with less care. Also only half of elderly has private house while about $10 \%$ live without home in mosques and churches [8]. It is estimated that $15 \%-50 \%$ of elderly are affected by malnutrition in the community while in hospital settings $20-60 \%$ of elderly are reported to be malnourished [9].

In Ethiopia, almost third of elderly has one or more visual, mobility, weakness or hearing difficulty which affects people's access, utilization of food. Moreover, some elderly have some pension while majority of the rural depends on their relative for support [8] .

Globally, malnutrition is estimated to affect one in every six population; it is still increasing along with increased aging [7]. Especially, those with cognitive decline, hospitalized or institutionalized are at greater risk of malnutrition than community dwellers. [7]. Similarly malnutrition results twice risk of long term mortality, three times increased risk of infection and longer period of hospitalization increasing health care costs. Malnutrition among elderly also increase rate of hospital readmission by $30 \%$ which places huge financial burdens on government and individuals [10]. Despite this huge burden, malnutrition is still under reported due to lack of regular malnutrition screening [6].

Malnutrition among old age above 65 years has devastating impact on morbidity, mortality, increasing health care cost and others [6]. A follow up study showed, at risk of malnutrition and malnourished had $60 \%$ and $33.7 \%$ cumulative survival after three years. Also hazards of all-cause mortality was increased by $56 \%$ to $71 \%[11]$.

Despite malnutrition is being major public health problem among elderly, there are limited studies in Ethiopia $[11,12]$ showing malnutrition is common problem affecting from $9 \%$ to $22 \%$ in northwest Ethiopia [13]. Along with limited studies, previous studies were unable to use appropriate screening tool and unable to pinpoint major predictors of malnutrition among elderly in Ethiopian setting for action to be taken. Thus, particular research was to generate reliable evidences on magnitude of malnutrition and its context specific risk factors using reliable and validated tool for better geriatric health.

\section{Objective of the study}

- To assess the nutritional status and predictors of malnutrition among elderly ( $>=65$ years) residing in Harari region, Eastern Ethiopia.

\section{Methods}

\section{Study Area and Period}


This study was conducted in Harari region, Eastern Parts of Ethiopia. Harar is found $526 \mathrm{~km}$ from Addis Ababa, capital city of Ethiopia. According to the Ethiopian central statics authority's 2007 report, Harari region has a total population of 183, 344 of whom 92,258 were men and 91,086 women and majority of its population lives in 99,321 or $54.17 \%$ of the population lives in urban (CSA 2007 report). Ethnic groups in the region include the Oromo (52.3\%), Amhara (32.6\%), Harari (7.1\%) and others like Tigre and Guraghe etc. According to 2010 Harari Region population projection there are 250, 093 with 146, 913 living in urban and 122, 942 are male with total house hold of 64, 334.

Based on the study Ethiopian demography 2018 [14], in Ethiopia 2.91\% are elderly. Using this conversion factor the expected number of elderly was calculated. This Quantitative cross sectional study was conducted from March 01 to 30, 2019.

\section{Population and eligibility}

All peoples age >=65 years of age in Harar region were the target population for this study to which the result is considered to be applied. While, those randomly selected people age greater than or equals to 65 years from the selected kebeles, were study population and included in the current survey. Those community dwellers aged above or equals to 65 years with or without their care givers residing in the selected kebles (lower administrative unit in Ethiopia) were included in the current survey. Those elderly who have no any caregiver and unable to communicate and give information were excluded from the study as we are unable to get reliable data from them. In addition, those who were not volunteers to take part in the survey were also excluded from the study. Study subjects with severe spinal curvature (kyphosis or scoliosis), both extremities amputation were not included in the study.

\section{Sample size determination}

To determine the minimum sample size for the first objective, single proportion samples size formula with $P$ as prevalence of malnutrition from the previous study (21.9) [13], 95 \% confidence level, " $Z$ " critical value at $95 \% \mathrm{Cl}$ and marginal error of " $d$ " 5\% and became 263. (see Formula 1 in the Supplementary Files)

For factors associated with malnutrition the sample size is determined using OpenEpiSave software for cross sectional survey taking empirical statistics like odds ratio, proportion of exposed with malnutrition and power of $80 \%$, with ratio of exposed to non-exposed as 1 and $5 \%$ level of significance. Taking the larger sample size calculated from objective two (286), design effect of 2, and 10\% non-response rate, the final sample size was $(572+0.1(572))=630$. Thus, this study tried to interview and include 630 study subjects (elderly).

\section{Sampling Procedures}

Multi stage sampling was used to select eligible elderly peoples from randomly selected Kebles from each Woreda. Then from each selected woredas using simple random sampling, we select two Kebles randomly from each woreda. Then the sample size was proportionally allocated for each respective 
selected woredas and then to the selected Kebles. Then, the data collector located the center of the kebeles and then randomly select a random direction using random spinning a pen. Then all HHs with elderly people were interviewed in that selected direction until the sample size is achieved. However, when the required sample size is not achieved, another random direction were selected in the similar way and data collected similarly.

\section{Methods of data Collection}

Data were collected using set of structured questionnaires including Socio demographic situations, Full Mini nutritional Assessment, Geriatrics Depression scale, psycho social issues and others. Data were collected by trained graduating health science students from house to house visit. Data collectors got the data by interviewing either their care giver if the subject is unable to communicate or the study subject directly in their local languages in Amharic, Harari, or Affan Oromo.

The full MNA tool is worldwide validated too with $80 \%$ specificity and $90 \%$ sensitivity making it as the best, effective, affordable and quick malnutrition screening tool among elderly. It has also showing greater importance in identifying over malnutrition and risk of malnutrition early, for effective public Health Interventions. Thus the full MNA tool was contextualized, translated to Amharic and pretested before data collection.

The weight of the subjects were measured using calibrated electronic weighting scale to the nearest $0.1 \mathrm{~kg}$. The height was measured using adult stadiometre for those who can stand. While for those who are unable to stand the Arm span from the sterna notch to tip of finger or knee height was to be used as proxy indicator for height of the subjects using specific formula for the specific sex, ethnic group. The $\mathrm{BMI}$ was calculated by dividing the weight in $\mathrm{Kg}$ by the height in $\mathrm{m}$ square and was expressed in $\mathrm{kg} / \mathrm{m}^{2}$. However when the height measurement is not possible, calf circumference was used instead of $\mathrm{BMI}$ and the status was classified according to the nestle recommendations.

The mid upper arm circumference (MUAC) was measured using non-stretchable tape meter on the left arm at midpoint between the acromion process of clavicle and elbow joint. It was measured in arm extended and recorded in centimeter. Short twenty four hour dietary recall was used to assess the dietary intake pattern of the clients, as it reduce the recall bias secondary to memory lapse.

The Geriatric depression score was used to assess the psychological condition off the elderly. A fifteen item depression scale assessment were used by direct interviewing the respondent. This tool has shown almost equal sensitivity in identifying depression level which have direct influence on malnutrition among elderly.

\section{Data Quality Assurance}

Pair of trained graduating health students were employed to collect the data from study subjects as anthropometric measurement need curiosity and two individuals during measurement. Two day training 
appropriate interview techniques, anthropometric measurements like height and weight, practices were performed before actual data collection. After that constructive feedbacks were given for the data collectors by investigators and supervisor until they become clear of the checklist implementation. Anthropometric reliability assessment were done on 10 study subjects and inter and interobserver variation were calculated. Cranach's Alpha measure of reliability used and kappa above 0.7 were considered acceptable and all within the acceptable range. All standard measuring procedures and instruments were strictly followed while data collection. During data entry in to EpiData the data quality was kept by making legal ranges, skipping patterns, appropriate coding and careful data entry. The intra observer and inter observers technical error of measurement were calculated after training of the data collectors and supervisors, to measure the reliability of the weight and height anthropometric measurements.

\section{Methods of Data Analysis}

After checking for completeness ad inconsistencies, the collected data were entered in to EpiData Version 3.02 and Exported to SPSS version 20.0 for analysis. The data is presented in tables, graphs, percentages, frequencies, mean, medians and standard deviations. After measurement of weight and height, body mass index was calculated automatically. Similarly geriatric depression score was computed using the compute command. The outcome variable malnutrition status was categorized as those with malnutrition, at risk of malnutrition and normal nutritional status based on the overall sum score of each subject. Malnutrition was assessed using the full MNA score (out of 30) and calculated using the compute command in SPSS. Those who scored below 17 (malnourished), 17 to 23.5 (at risk of malnutrition) and otherwise normal [7]. At the same time the GDS was calculated using 15 items yes or no (1-yes for the presence of one of the depression symptoms. A GDS of 10 to 15 were considered as severe while, 5 to 9 as mild depression and no depression otherwise.

Then both bivariate and multivariable ordinal logistic regression were conducted using crude and adjusted odds Ratio at $95 \%$ confidence interval reported. The odds ratio corresponding to each variable were calculated using PLum command and by exporting the result to excel as needed. Those variables with $P$ value less than 0.20 and important predictors in bivariate analysis were taken to multivariable ordinal logistic regression analysis. $P$ value less than 0.05 at multivariable analysis were declared as statistically significant association.

\section{Variables}

Nutritional status of elderly (ordinal scale) was the dependent variable whereas, demographic variables (age, sex, income, occupation, pension, education, and parental support), smoking, depression, appetite, chronic disease, oral health problems and physical exercise were independent variables.

\section{Ethical considerations}


Ethical clearance was taken from Dire Dawa University Research and Technology Interchange directorate. Then, it was forwarded to Harari health bureau then to respective woredas and Kebles. Verbal informed consent were obtained from the respondents who are able to give consent otherwise it will be taken from caregivers or their parents. The data is used only for this research only and also in the future. Personal identification of clients like name, personal location and others were not be recorded. For those having severe malnutrition, nutritional counseling were done. In addition, counseling in order to have health care service in the nearest health facility were advised in advance for them and caregiver.

\section{Results}

\section{Basic characteristics of Elderly}

In this particular study, a total of 592 respondents were recorded with overall response rate of $93.4 \%$. Regarding religion, a total of 290 (50.3\%) and 244 (42.4\%) were followers of Islam and orthodox Christianity respectively. Almost half, 292 (49.3\%) were married followed by 212 (35.8) of their partner has died. Majority of them, $316(54 \%)$ were illiterate while, 176(30.1\% attended primary school. Majority of respondents, $508(85.8 \%)$ and $522(88.2 \%)$ were from rural area and live with their relatives respectively. With respect to occupation of respondents, 308(52\%) and $209(35.3 \%)$ reported that they do not have work and involved in private work. A total of $406(69.2 \%)$ reported that they did not have any pension fee.

Table 1 Basic characteristics of elderly peoples in Harari Region, Eastern Ethiopia, 2019 


\begin{tabular}{|c|c|c|c|}
\hline \multicolumn{2}{|l|}{ Characteristics } & \multirow{2}{*}{$\begin{array}{l}\text { Number } \\
291\end{array}$} & \multirow{2}{*}{$\begin{array}{l}\text { Percen } \\
49.2\end{array}$} \\
\hline $\operatorname{Sex}(n=592)$ & Male & & \\
\hline & Female & 301 & 50.8 \\
\hline \multirow[t]{4}{*}{ Religion $(n=576)$} & Muslim & 290 & 50.3 \\
\hline & Orthodox & 244 & 42.4 \\
\hline & Protestant & 40 & 6.9 \\
\hline & Catholic & 2 & 0.3 \\
\hline \multirow[t]{4}{*}{ Marital Status $(n=592)$} & Married & 292 & 49.3 \\
\hline & Single & 18 & 3.0 \\
\hline & Divorced & 70 & 11.8 \\
\hline & Widowed & 212 & 35.8 \\
\hline \multirow[t]{4}{*}{ Educational Status $(\mathrm{n}=585)$} & Illiterate & 316 & 54.0 \\
\hline & Primary School & 176 & 30.1 \\
\hline & Grade 8-12 & 66 & 11.3 \\
\hline & College And Above & 27 & 4.6 \\
\hline \multirow[t]{2}{*}{ Residence $(n=592)$} & Urban & 84 & 14.2 \\
\hline & Rural & 508 & 85.8 \\
\hline \multirow[t]{2}{*}{ Live With $(\mathrm{n}=592)$} & Alone & 70 & 11.8 \\
\hline & With Others & 522 & 88.2 \\
\hline \multirow[t]{2}{*}{ Do You Work At The Moment Pension Fee $(n=587)$} & Yes & 271 & 46.2 \\
\hline & No & 316 & 53.8 \\
\hline \multirow[t]{2}{*}{ Who Cover Your Expense $(n=585)$} & Yes & 258 & 43.6 \\
\hline & No & 327 & 55.2 \\
\hline \multirow[t]{2}{*}{ Health Insurance $(\mathrm{n}=586)$} & Yes & 94 & 16 \\
\hline & No & 492 & 84 \\
\hline \multirow[t]{3}{*}{ Occupation $(\mathrm{n}=590)$} & Farmer & 39 & 6.6 \\
\hline & Private & 209 & 35.3 \\
\hline & Government & 34 & 5.7 \\
\hline
\end{tabular}




\begin{tabular}{llll} 
& Not Have Work & 308 & 52.0 \\
\hline Pension Fee $(\mathrm{n}=587)$ & Yes & 168 & 28.6 \\
\cline { 2 - 4 } & No & 406 & 69.2 \\
\cline { 2 - 4 } & Not Reached & \multirow{2}{*}{13} & 2.2 \\
\hline
\end{tabular}

Regarding perceived health status of elderly, about $37 \%, 47 \%$ and $16 \%$ of them perceived as good, average and poor respectively (Figure 2).

Table 2 Lifestyle related characteristics of Elderly people In Harari Region, Eastern Ethiopia.

\begin{tabular}{llll}
\hline \multicolumn{1}{c}{ Characteristics } & & number & Frequency \\
\hline Khat Chewing & Yes & 210 & 35.5 \\
\cline { 2 - 4 } & No & 383 & 64.5 \\
\hline Cigarette smoking & Yes & 48 & 8.1 \\
\cline { 2 - 4 } & No & 532 & 89.9 \\
\hline Chronic Illness & Yes & 349 & 59.0 \\
\cline { 2 - 4 } & No & 243 & 41.0 \\
\hline Insomnia & Yes & 330 & 55.7 \\
\cline { 2 - 4 } & No & 262 & 44.3 \\
\hline Hospitalization during the last one year & Yes & 196 & 33.1 \\
\cline { 2 - 4 } & No & 396 & 66.9 \\
\hline Have chewing problem & Yes & 381 & 64.4 \\
\cline { 2 - 4 } & No & 211 & 35.6 \\
\hline & Yes & 135 & 22.8 \\
\cline { 2 - 4 } & No & 457 & 77.2 \\
\hline
\end{tabular}

Regarding lifestyle characteristics, a total of 210 (35.5\%) had habit of khat chewing. While about 48 (8.1\%) smoke cigarette. In addition, 349 (59\%) and 330 (55.7\%) had at least one chronic illness and insomnia respectively with 196 (33.1\%) had history of hospitalization in the previous year. However, only $135(22.8 \%)$ had habit of physical activity. More than half, 381(644\%) reported to have some sort of denture problem or eating problem (Table 2). 
Table 3 Detail report on the outcomes of GDS short form screening for elderly people in Harari Region, Eastern Ethiopia. 
GDS dimensions

Are You basically Satisfied with your life?

Are You basically Satisfied with your life?

Have you dropped many of your activities and interests?

Do you feel that your life is empty?

Do you often got bored?
Are you in a good sprit most of time?

Are you in a good sprit most of time?

Are you afraid that something bad is going to happen to you?

Do you feel happy most of the time?

Do you often feel hopeless?

Do you prefer to stay at home rather than going out?

Do you feel that you have more problem with memory than most?

Do you feel that you have more problem with memory than most?

Dou think it is wonderfulto be a ivew?

Do you think it is wonderful to be alive now?

\begin{tabular}{llll} 
& No & 148 & 25.0 \\
\hline Do you feel worthless the way you are now? & Yes 87 & 14.7 \\
\cline { 2 - 4 } & No & 505 & 85.3 \\
\hline Do you feel full of energy? & Yes 298 & 50.3 \\
\cline { 2 - 4 } & No 294 & 49.7 \\
\hline Do you feel that your situation is hopeless? & Yes 81 & 13.7 \\
\cline { 2 - 4 } & No 511 & 86.3
\end{tabular}

\begin{tabular}{lll} 
Yes & 526 & 88.9 \\
\hline No & 66 & 11.1 \\
\hline
\end{tabular}

\begin{tabular}{lll} 
Yes & 197 & 33.3 \\
\hline No & 395 & 66.7 \\
Yes & 74 & 12.5 \\
\hline No & 518 & 87.5
\end{tabular}

\begin{tabular}{lll} 
Yes & 118 & 19.9 \\
\hline No & 474 & 80.1
\end{tabular}

\begin{tabular}{lll} 
Yes & 421 & 71.1 \\
\hline No & 171 & 28.9 \\
\hline Yes & 112 & 18.9 \\
\hline No & 480 & 81.1
\end{tabular}

\begin{tabular}{lll} 
Yes & 444 & 75.0 \\
\hline No & 148 & 25.0 \\
\hline
\end{tabular}

\begin{tabular}{lll} 
Yes & 100 & 16.9 \\
\hline No & 492 & 83.1
\end{tabular}

\begin{tabular}{lll} 
Yes & 227 & 38.3 \\
\hline No & 365 & 61.7
\end{tabular}

\begin{tabular}{lll} 
Yes & 140 & 23.6 \\
\hline No & 452 & 76.4 \\
\hline
\end{tabular}

\begin{tabular}{lll} 
Yes & 444 & 75.0 \\
\hline No & 148 & 25.0 \\
\hline
\end{tabular}

Frequency Percentage 
In general, a total of 187 (31.6\%) of respondents had screening positive for geriatric depression with 131 (22.1\%) and 56 (9.5\%) had moderate (GDS score of 5 to 9 ) and severe depression (GDS score of 10 to 15) respectively. While, more than half, 405 (68.4\%) were negative (no depression) for Geriatric depression screening tool short version.

\section{Nutritional status of Elderly people}

As shown in the figure (3), majority 306 (51.7\%) and 193 (32.1\%) were found to be at risk of malnutrition (MNA score from 17 to 24) and not malnourished (MNA score greater than or equals to 24). While, 93 (15.7\%) were malnourished (MNA score below 17) according to full MNA malnutrition screening tool.

\section{Factors Associated with Malnutrition among elderly}

Table 4 Factors associated with Malnutrition among elderly people in Harari region, Eastern Ethiopia. 


\begin{tabular}{lll}
\hline Malnourished & At risk of malnutrition & Normal \\
No (freq.) & No (freq.) & No
\end{tabular}

(freq.)

\begin{tabular}{|c|c|c|c|c|c|c|c|c|}
\hline \multirow[t]{2}{*}{ Sex } & Male & 43 & $15 \%$ & 147 & $51 \%$ & 101 & $35 \%$ & \multirow[t]{2}{*}{$1.16(0.281)$} \\
\hline & Female & 50 & $17 \%$ & 159 & $53 \%$ & 92 & $31 \%$ & \\
\hline \multirow[t]{2}{*}{ Live with whom } & Alone & 8 & $11 \%$ & 37 & $53 \%$ & 25 & $36 \%$ & \multirow[t]{2}{*}{$0.95(0.329)$} \\
\hline & With others & 85 & $16 \%$ & 269 & $52 \%$ & 168 & $32 \%$ & \\
\hline \multirow[t]{2}{*}{ Religion } & Muslim & 69 & $24 \%$ & 151 & $52 \%$ & 70 & $24 \%$ & \multirow[t]{2}{*}{$34.2(0.000)$} \\
\hline & Christian & 24 & $8 \%$ & 155 & $51 \%$ & 123 & $41 \%$ & \\
\hline \multirow[t]{3}{*}{ Marital status } & Married & 24 & $8 \%$ & 157 & $54 \%$ & 111 & $38 \%$ & \multirow[t]{3}{*}{$42.3(0.000)$} \\
\hline & Divorced & 13 & $15 \%$ & 55 & $63 \%$ & 20 & $23 \%$ & \\
\hline & Widowed & 56 & $26 \%$ & 94 & $44 \%$ & 62 & $29 \%$ & \\
\hline \multirow[t]{5}{*}{ Educational status } & Illiterate & 76 & $24 \%$ & 153 & $48 \%$ & 87 & $28 \%$ & \multirow{5}{*}{$\begin{array}{l}32.16 \\
(0.000)\end{array}$} \\
\hline & \multirow{2}{*}{$\begin{array}{l}\text { Primary } \\
\text { school }\end{array}$} & 13 & $7 \%$ & 104 & $59 \%$ & 59 & $34 \%$ & \\
\hline & & & & & & & & \\
\hline & Grade8 & 4 & $4 \%$ & 49 & $49 \%$ & 47 & $47 \%$ & \\
\hline & above & & & & & & & \\
\hline \multirow[t]{2}{*}{ Work at the moment } & Yes & 11 & $4 \%$ & 144 & $53 \%$ & 116 & $43 \%$ & \multirow[t]{2}{*}{$53.4(0.000)$} \\
\hline & No & 80 & $25 \%$ & 162 & $51 \%$ & 74 & $23 \%$ & \\
\hline \multirow[t]{5}{*}{ Occupation } & Farmer & 1 & $3 \%$ & 19 & $49 \%$ & 19 & $49 \%$ & \multirow{5}{*}{$\begin{array}{l}47.60 \\
(0.000)^{*}\end{array}$} \\
\hline & Private & 11 & $5 \%$ & 111 & $53 \%$ & 87 & $42 \%$ & \\
\hline & Government & 1 & $3 \%$ & 20 & $59 \%$ & 13 & $38 \%$ & \\
\hline & Not have & 79 & $26 \%$ & 155 & $50 \%$ & 74 & $24 \%$ & \\
\hline & work & & & & & & & \\
\hline \multirow[t]{2}{*}{ Residence } & Urban & 4 & $5 \%$ & 35 & $43 \%$ & 42 & $52 \%$ & \multirow{2}{*}{$\begin{array}{l}18.41 \\
(0.000)\end{array}$} \\
\hline & Rural & 87 & $17 \%$ & 271 & $53 \%$ & 150 & $30 \%$ & \\
\hline \multirow[t]{2}{*}{ Who covers your } & Yes & 13 & $5 \%$ & 140 & $54 \%$ & 105 & $41 \%$ & \multirow{2}{*}{$\begin{array}{l}6.16 \\
(0.013)^{*}\end{array}$} \\
\hline & No & 77 & $24 \%$ & 164 & $50 \%$ & 86 & $26 \%$ & \\
\hline
\end{tabular}




\begin{tabular}{|c|c|c|c|c|c|c|c|c|c|}
\hline \multirow[t]{2}{*}{ Health insurance } & & Yes & 5 & $5 \%$ & 53 & $56 \%$ & 36 & $38 \%$ & \multirow[t]{2}{*}{$34.6(0.000)$} \\
\hline & & No & 85 & $17 \%$ & 252 & $51 \%$ & 155 & $32 \%$ & \\
\hline \multirow[t]{2}{*}{ Pension fee } & & Yes & 34 & $20 \%$ & 85 & $51 \%$ & 49 & $29 \%$ & \multirow[t]{2}{*}{$3.3(0.071)^{*}$} \\
\hline & & No & 59 & $14 \%$ & 221 & $52 \%$ & 144 & $34 \%$ & \\
\hline \multirow{2}{*}{\multicolumn{2}{|c|}{ Chronic pain }} & Yes & 89 & $26 \%$ & 179 & $51 \%$ & 81 & $23 \%$ & \multirow{2}{*}{$\begin{array}{l}67.1 \\
(0.0001)\end{array}$} \\
\hline & & No & 4 & $2 \%$ & 127 & $52 \%$ & 112 & $46 \%$ & \\
\hline \multirow{2}{*}{\multicolumn{2}{|c|}{ Insomnia }} & Yes & 71 & $22 \%$ & 169 & $51 \%$ & 90 & $27 \%$ & \multirow{2}{*}{$\begin{array}{l}20.3 \\
(0.0001)\end{array}$} \\
\hline & & No & 22 & $8 \%$ & 137 & $52 \%$ & 103 & $39 \%$ & \\
\hline \multirow{2}{*}{\multicolumn{2}{|c|}{ Khat chewing }} & Yes & 20 & $10 \%$ & 114 & $54 \%$ & 76 & $36 \%$ & \multirow[t]{2}{*}{$6.58(0.01)$} \\
\hline & & No & 72 & $19 \%$ & 192 & $50 \%$ & 117 & $31 \%$ & \\
\hline \multirow{2}{*}{\multicolumn{2}{|c|}{ Smoking }} & Yes & 71 & $22 \%$ & 169 & $51 \%$ & 90 & $27 \%$ & \multirow[t]{2}{*}{$4.26(0.039)$} \\
\hline & & No & 22 & $8 \%$ & 137 & $52 \%$ & 103 & $39 \%$ & \\
\hline \multirow{2}{*}{\multicolumn{2}{|c|}{$\begin{array}{l}\text { Hospitalization } \\
\text { previous year }\end{array}$}} & Yes & 60 & $31 \%$ & 99 & $51 \%$ & 37 & $19 \%$ & \multirow[t]{2}{*}{$57.3(0.0001)$} \\
\hline & & No & 33 & $8 \%$ & 207 & $52 \%$ & 156 & $39 \%$ & \\
\hline \multirow{2}{*}{\multicolumn{2}{|c|}{ Chewing problem }} & Yes & 70 & $18 \%$ & 197 & $52 \%$ & 114 & $30 \%$ & \multirow[t]{2}{*}{$6.7(0.01)$} \\
\hline & & No & 23 & $11 \%$ & 109 & $52 \%$ & 79 & $37 \%$ & \\
\hline \multirow{2}{*}{\multicolumn{2}{|c|}{ Physical exercise }} & Yes & 15 & $11 \%$ & 75 & $56 \%$ & 45 & $33 \%$ & \multirow[t]{2}{*}{$1.2(0.296)$} \\
\hline & & No & 78 & $17 \%$ & 231 & $51 \%$ & 148 & $32 \%$ & \\
\hline \multirow{3}{*}{\multicolumn{2}{|c|}{ Depression }} & Depression & 75 & $40 \%$ & 84 & $45 \%$ & 28 & $15 \%$ & \multirow{3}{*}{$\begin{array}{l}106.02 \\
(0.0001)\end{array}$} \\
\hline & & No & 18 & $4 \%$ & 222 & $55 \%$ & 165 & $41 \%$ & \\
\hline & & depression & & & & & & & \\
\hline
\end{tabular}

Table 5 Bivariate ordinal logistic regression output for prediction of malnutrition among elderly. 


\begin{tabular}{llllll}
\hline Variables & $\beta$ & Sef $\beta$ & $\operatorname{Exp}(\beta)$ OR & P-value & $95 \%$ CI $(\beta)$ \\
\hline Sex (female) & .172 & .157 & 1.19 & 0.272 & $-0.14-0.48$ \\
\hline Residence (Rural) & .997 & .235 & 2.71 & 0.000 & $0.54-1.46$ \\
\hline Education (higher) & -.565 & .107 & 0.57 & 0.000 & $-0.78--0.36$ \\
\hline Living (with others) & .224 & .243 & 1.25 & 0.357 & $-0.253-0.70$ \\
\hline Marital status (separate) & .380 & .088 & 1.46 & 0.000 & $0.21-0.55$ \\
\hline Pension (yes) & .298 & .176 & 1.35 & 0.091 & $-0.05-0.64$ \\
\hline Work at the moment (No) & 1.173 & .168 & 3.23 & 0.000 & $0.85-1.50$ \\
\hline Support (yes) & -.919 & .165 & 0.40 & 0.000 & $-1.24-0.60$ \\
\hline Health insurance (yes) & -.484 & .216 & 0.62 & 0.025 & $-0.91-0.06$ \\
\hline Chronic pain (Yes) & 1.346 & .171 & 3.84 & 0.000 & $1.01-1.68$ \\
\hline Hospitalization (Yes) & 1.272 & .179 & 3.57 & 0.000 & $0.92-1.62$ \\
\hline Insomnia (yes) & .700 & .161 & 2.01 & 0.000 & $0.38-1.02$ \\
\hline Physical activity (No) & .171 & .187 & 1.19 & 0.359 & $-0.20-0.54$ \\
\hline Depression (yes) & 1.986 & .200 & 7.29 & 0.000 & $1.59-2.38$ \\
\hline
\end{tabular}

Those respondents on pension, residing rural, with economic shortages, without health insurance, suffering from chronic pain, previous hospitalizations and positive for depression were predictors of malnutrition among elderly. Old ages from rural had higher log odds for being malnourished. Similarly, older age with history of chronic pain (COR=170; $p=0.008)$ and hospitalization (COR =3.57; $p$ value less than 0.0001 ) had four fold higher odds of being malnourished (Table 5).

Table 6 parameters for predictors of malnutrition level as compared to normal and at risk of malnutrition (multivariable OLS model with stepwise backward regression method) 


\begin{tabular}{lccccc}
\hline Predictors & $\beta$ & $\operatorname{Sef} \beta$ & $\operatorname{Exp}(\beta)$ OR & P value & 95\% CI of Exp ( $\beta)$ \\
\hline Pension fee user (yes) & 0.268 & 0.205 & 1.31 & 0.192 & $0.87-1.95$ \\
\hline Residence (rural) & 0.731 & 0.259 & 2.08 & 0.005 & $1.25-3.45$ \\
\hline Cover personal expense (no) & 0.474 & 0.185 & 1.61 & 0.010 & $1.12-2.30$ \\
\hline Have health Insurance (no) & 0.458 & 0.250 & 1.58 & 0.067 & $0.97-2.58$ \\
\hline Chronic pain (yes) & 0.532 & 0.199 & 1.70 & 0.008 & $1.15-2.51$ \\
\hline Hospitalization in the last year (yes) & 0.464 & 0.205 & 1.59 & 0.023 & $1.27-2.38$ \\
\hline Depression (yes) & 0.233 & 0.028 & 1.26 & 0.001 & $1.20-1.34$ \\
\hline
\end{tabular}

The outcome variable, malnutrition is ordered in form of normal, at risk of malnutrition and malnourished. The OLS predict the probability of higher odds for malnutrition as compared to normal nutritional status by each predictor variables. The proportional odds assumption is partially full filled and other assumptions of OLS were met. The predicted regression coefficients are interpreted as predicted change in log odds of being malnourished as compared of normal per unit increase in predictor variables controlling for other variables. While, odds ratio is interpreted for categorical predictors.

The full model including important predictors of malnutrition among elderly, shows a significant improvement in model fitness under -2 log likelihood for the intercept only and with the full model (P less than 0.0001). In addition, both the deviance $(p=0.08)$ and pearson chi-square test $(P=0.01)$ were not significant (above 5\%) which showed better fitted OLS.

The predicted log odds of being malnourished (lower MNA score) was higher among those from rural residents $(\beta=0.73$ (se $=0.21), p=0.005)$. Elderly who are not on work and on pension ( $A O R=1.3195 \%$ $\mathrm{Cl}$ : 0.87-1.95) and did not have health insurance (AOR $=1.58 ; 95 \% \mathrm{Cl} ; 0.97-2.58)$ had $31 \%$ and $58 \%$ higher predicted odds of being malnourished than those who are on work respectively. In addition, those who have chronic pain history $(\mathrm{AOR}=1.70 ; 95 \% \mathrm{Cl}: 1.15-2.51)$, previous hospitalization $(\mathrm{AOR}=1.59: 95 \% \mathrm{Cl}$ : 1.27-2.38) and not able to cover their personal expense (AOR $=1.61: 95 \% \mathrm{Cl}: 1.12-2.30$ ) were $70 \%, 60 \%$ and $61 \%$ significantly higher log odds of being malnourished (lower MNA score than higher) respectively. The relationship between previous hospitalizations with malnutrition among elderly is moderated significantly by the presence of chronic pain $(\beta=0.113, p=0.015)$.

\section{Discussion}

This study was aimed to assess the magnitude of malnutrition risk and its predictors among elderly in eastern part of Ethiopia. The finding revealed that, $32.1 \%$ (28.2\% - 35.8\%) and $15.7 \%(12.8 \%-18.6 \%)$ were at risk of malnutrition and malnourished based on validated MNA screening tool respectively. This is indicative of high risks of malnutrition and all its bad consequences in overall health of individual (12). 
Similarly, evidences from other regions of Ethiopia showed 28.3\% [15], 22\% [16], 21.9\% [13], 17.6\% (95\% Cl: 15.0 - 20.2) [17], 17.1\% [18], 12.5\% in Sirilanka [19] and 24.8\% in Nepal [20] were malnourished.

This burden of malnutrition can still be above this, due to potentially higher incidence of risk factors for malnutrition. It might be expected that the burden will be higher among institutionalized elders frailty in institutionalized persons $(\beta: 0.22 ; \mathrm{P}=0.036)$ [21]. However, the current study incorporate both urban $(4.9 \%)$ and rural area $(17.1 \%)$ which makes representative. In addition, the use of BMI as tool to screen for malnutrition instead of MNA tool, may make a differences even if, it has high predictive power for malnutrition [15].

Rural residents were found to be an increased risk of being malnourished as compared to urban residents $(A O R=2.08 ; 95 \% \mathrm{Cl}: 1.25-3.45)$. This is attributed to difference in socioeconomic status, dietary habit and other confounding factors make rural area at risk of malnutrition. It may also be related to lower access to health care, sanitation facility and educational status which makes disease and food intake shortage a major problem [22, 23].

Economic dependences characterized by being pension user, not able to cover personal expense and without any health insurance were vulnerable to a higher probability of being malnourished. These economic instabilities decrease food access and dietary diversity ultimately resulting in malnutrition among elderly. One study showed that less diversified diet intake increase risk of malnutrition among elderly [17]. This indicates the need for strategies and interventions targeting the basic and underlying context specific causes of malnutrition in addition to addressing immediate causes [24]. Other study also showed that economic inaccessibility were important risk factors for malnutrition [25]. Furthermore evidence showed that presence of disposable income is positively related to self-rated health status among old age $(\mathrm{OR}=1.8)[26]$.

Depression is found to increase the nutritional risk among elders (AOR=1.26: 95\% Cl: 1.20-1.34). One study indicated that, depression symptom significantly increase nutritional risk ((MNA score 22.86 vs. 24.96, $p<0.001$ ) [27]. As depression is not normal part of aging, rather common mood disorder that significantly affect the dietary intake and physiology which potentially affect the nutritional status. These may be related to increased nutrition risk due to hospitalization ( $p$ value less than 0.0001 ) and not involved actively in work ( $p$-value less than 0.0001) which makes them less active and at risk for depressive disorder. There should be screening and care for depression among elderly in health facilities. In addition, promoting active living style and reducing sedentary lifestyle could play an important role in reducing malnutrition and adverse consequences [28-30].

Furthermore, the presence of chronic illness and hospitalization with multiple drug use are important predictors of malnutrition. A review of evidence showed that multiple drug intake negatively affect the nutritional status of elderly $(\beta:-0.62 ; P=0.001)$. Also those elders in institutions other than home setting increase the risk of being malnutrition. [21, 29]. Thus, interventions developing positive lifestyle like physical activity and quality dietary habit for reduced chronic diseases risk should get due attention. The 
inclusion elderly peoples as target for nutrition and health interventions for better health status should be given due attention.

However, other confounding situations and variables may interact together to the deterioration of their nutritional status among institutionalized elders [31]. More specifically, the presence of chronic illness, poor caring practice and psychological status may affect food intake and nutritional status. In addition, polypharmacy may have the potential to decrease food intake and other side effects which might increase malnutrition risk [32].

The findings of this study employed validated tool with overall accuracy of $91 \%$ (sensitivity and specificity of $87.9 \%$ and $89.6 \%$ for the established cutoff points) [33]. It also employed valid and reliable anthropometric measurements for better outputs. However, the cross-sectional nature of the study, some age related disorders (curvatures) may create some errors. The result should be viewed in the lights of the above strength and weakness of the study. But, the study pinpoint an important health problem of the neglected society in Ethiopia for programs to design and implement effective interventions addressing elderly.

\section{Conclusion And Recommendations}

Malnutrition among old age is public health concern that needs attention. Economic vulnerability, residence, depression, presence of chronic disease and hospitalization were an important risk factors for malnutrition among old age. The health system need to give attention o geriatric health and implement screening, health education and follow up of elderly nutritional status.

\section{Abbreviations}

Cl: Confidence Interval

EMR: Electronic Medical record

OLR: Ordinal Logistic Regression

OR: Odds Ratio

\section{Declarations}

\section{Availability of data and materials}

All data generated or analyzed during this study are included in this published article.

\section{Acknowledgements}


We thank heath offices, Dire Dawa University, data collectors, and supervisors for their valuable contribution for accomplishment of this study.

\section{Funding}

We thank Dire Dawa University for providing financial and administrative support grant for our research.

\section{Author Information}

Abdu Oumer: ${ }^{1 *}$ corresponding author: department of Public Health, University, Ethiopia. Email: phnabu@gmail.com

Imam Dagne ${ }^{2}$ Department of Public Health, Dire Dawa University, Eastern Ethiopia

Ahmed Ali: ${ }^{3}$ Lecturer, School of medicine, Dire Dawa University, Eastern Ethiopia

\section{Authors' contributions}

AO participated in from initial inception, proposal writing, preparing data collection tool, pretesting, data collection, data analysis, result write up, preparation of manuscript to submission. ID and AA participated in inception, preparing data collection tool, pretesting, data collection, and review the final submission.

\section{Corresponding Author}

Abdu Oumer; Email: phnabu@gmail.com

\section{Ethics Delarations}

\section{Ethics approval and consent to participate}

The research was reviewed and ethically approved by independent Research ethical review committee. Then a verbal informed consent considering their free will to participate in the study, confidentiality of their information and each participant was giving informed consent on separate paper and then they were eligible for the questionnaire. All possible ethical cares were respected throughout the conduct of research project.

Consent to Publish: Not Applicable

Competing interests

Authors declare that they have no competing interest

\section{References}


1. Wan He, D.G., and Paul Kowal, An Aging World: 2015: International Population Reports, U.S. Census Bureau, et al., Editors. 2016.

2. (UNECA), U.N.E.C.f.A., The Demographic Profiles of African Countries, United Nation Economic Commission for Africa, Editor 2016: Addis Ababa. p. 10-20.

3. Charles T, Assefa H, Tesfayi G and Hassan A., Population Dynamics, Food/Nutrition Security and Health in Ethiopia: Delicate Balance of Vulnerability \& Resilience. , F.a.N. Security, Editor 2009: IUSSP Marrakech. p. 1-4.

4. WHO, Global health and Aging, D.o.H.a.H. Services, Editor 2016, National Institute on Aging/Health, USA: USA.

5. RibeiRo, R., M. RoSa and M. Bozzetti, Ribeiro RS, Rosa MI, Bozzetti MC. Malnutrition and associated variables in an elderly population of Criciúma, SC. Rev Assoc Med Bras (1992), 2011. 57(1): p. 56-61.

6. Leslie, W. and C. Hankey, Aging, Nutritional Status and Health. Healthcare, 2015. 3: p. 648-658.

7. Nestle Nutrition Institute, A guide to completing the Mini Nutritional Assessment - Short Form (MNA®-SF, 2006, Nestle Nutrition Institute.

8. Help Age International, Vulnerability of Older People in Ethiopia: The Case of Oromia, Amhara and SNNP Regional States, 2013, HelpAge International in Ethiopia: Addis Ababa.

9. Pearce, S. Nutrition and Malnutrition in the Elderly. 2014 [cited December 7, 2018; Available from: http://www.uth.tmc.edu/hgec/GemsAndPearls/healthPromotions_Nutrition.html.

10. Cawood, A., M. Elia and R. Stratton, Systematic review and meta-analysis of the effects of high protein oral nutritional supplements. Ageing Res Rev 2012, 2012. 11: p. 278-296.

11. Söderström, L., Nutritional status among older people Risk factors and consequences of malnutrition, in Department of Public Health and Caring Sciences, Clinical Nutrition and Metabolism 2013, Uppsala University: Västerås.

12. van Bokhorst-de van der Schueren MA, Lonterman-Monasch S, de Vries OJ, Danner SA, Kramer MH, et al., Prevalence and determinants for malnutrition in geriatric outpatients. . Clinical Nutrition, 2013. 32 (6): p. 1007-1011.

13. Tessfamichael, D., A.A. Gete and M.M. Wassie, High Prevalence of Undernutrition among Elderly People in Northwest Ethiopia: A Cross Sectional Study. Journal of Nutritional Health and Food Sciences, 2014. 2(4): p. 1-5.

14. Mundi, I. Ethiopian Demographic profile 2017. Https://www.indexmundi.com/ethiopia/demographics_profile.html. World Countries fact book 2017 [cited 2018 Dec 29].

15. Hailemariam, H., P. Singh and T. Fekadu, Evaluation of mini nutrition assessment (MNA) tool among community dwelling elderly in urban community of Hawassa city, Southern Ethiopia. BMC Nutrition, 2016. 2(1): p. 11.

16. Adhana, Z., G. Tessema and G. Getie, Prevalence of Undernutrition and associated factors among people of old age in Debre Mrkos Town, North west Ethiopia. J Aging Res Clin Practice, 2019. 8: p. 20- 
26.

17. Legesse $\mathrm{M}$, Abebe $\mathrm{Z}$ and Woldie $\mathrm{H}$, Chronic energy deficiency and associated factors among older population in Ethiopia: A community based study. PLOS ONE, 2019. 14(4): p. e0214861.

18. Kidest W., Asseffa NA., Gemebo TD. and Astawesegn FH., Predictors of undernutrition among the elderly in Sodo zuriya district Wolaita zone, Ethiopia. BMC Nutrition, 2019. 5(1): p. 50.

19. Damayanthi, H.D.W.T., F.M. Moy, K.L. Abdullah and S.D. Dharmaratne, Prevalence of malnutrition and associated factors among community-dwelling older persons in Sri Lanka: a cross-sectional study. BMC Geriatrics, 2018. 18(1): p. 199.

20. Tamang, M.K., U.N. Yadav, H. Hosseinzadeh, B. Kafle, G. Paudel, et al., Nutritional assessment and factors associated with malnutrition among the elderly population of Nepal: a cross-sectional study. BMC Research Notes, 2019. 12(1): p. 246.

21. Fávaro-Moreira, N.C., S. Krausch-Hofmann, C. Matthys, C. Vereecken, E. Vanhauwaert, et al., Risk Factors for Malnutrition in Older Adults: A Systematic Review of the Literature Based on Longitudinal Data. Advances In Nutrition, 2016. 7(3): p. 507-522.

22. Visvanathan, R., J. Newbury and I. Chapman, Malnutrition in older people Screening and management strategies. Journal of Australian Family Physician 2004. 33(10): p. 799-806.

23. Kristi, J., M. Carla and P. Barry, Underweight, Undernutrition, and the Aging. Today's Research on Aging, 2007(8): p. 1-5.

24. Timpini, A., E. Facchi, S. Cossi, M.K. Ghisla, G. Romanelli, et al., Self-reported socio-economic status, social, physical and leisure activities and risk for malnutrition in late life: $A$ cross-sectional population-based study. The journal of nutrition, health \& aging, 2011. 15(3): p. 233-238.

25. Donini, L.M., P. Scardella, L. Piombo, B. Neri, R. Asprino, et al., Malnutrition in elderly: Social and economic determinants. The journal of nutrition, health \& aging, 2013. 17(1): p. 9-15.

26. Woo, J., R. Yu, K. Cheung and E.T.C. Lai, How Much Money Is Enough? Poverty and Health in Older People. The journal of nutrition, health \& aging, 2020.

27. German, L., I. Feldblum, N. Bilenko, H. Castel, I. Harman-Boehm, et al., Depressive symptoms and risk for malnutrition among hospitalized elderly people. The Journal of Nutrition Health and Aging, 2008. 12(5): p. 313.

28. Masanovic, B., S. Popovic, D. Bjelica and G. Zoric. The effects of physical activity on depressive symptoms among elderly people: a systematic review. in World Congress of Performance Analysis of Sport XIIAt. 2018. Opatija.

29. O'Keeffe, M., M. Kelly, E. O'Herlihy, P.W. O'Toole, P.M. Kearney, et al., Potentially modifiable determinants of malnutrition in older adults: A systematic review. Clinical Nutrition, 2019. 38(6): p. 2477-2498.

30. Jung, S.E., A.J. Bishop, M. Kim, J. Hermann, G. Kim, et al., Nutritional Status of Rural Older Adults Is Linked to Physical and Emotional Health. Journal of the Academy of Nutrition and Dietetics, 2017. 117(6): p. 851-858. 
31. Fávaro-Moreira, N.C., S. Krausch-Hofmann, C. Matthys, C. Vereecken, E. Vanhauwaert, et al., Risk Factors for Malnutrition in Older Adults: A Systematic Review of the Literature Based on Longitudinal Data. Advances In Nutrition, 2017: p. 507-22.

32. Jyrkkä J, Enlund H, Lavikainen P, Sulkava R and Hartikainen S., Association of polypharmacy with nutritional status, functional ability and cognitive capacity over a three-year period in an elderly population. Pharmacoepidemiol Drug Saf 2011. 20: p. 514-22.

33. Woldekidan, M.A., D. Haile, B. Shikur and S.H. Gebreyesus, Validity of Mini Nutritional Assessment tool among an elderly population in Yeka sub-city, Addis Ababa, Ethiopia. South African Journal of Clinical Nutrition, 2020: p. 1-7.

\section{Figures}




\section{Harari Region}

Total population $=250,093$

$$
\begin{gathered}
\mathrm{N}=7130 \\
\mathrm{n}=630
\end{gathered}
$$

From the total 9 woredas in the region, four randomly selected

\begin{tabular}{|c|c|c|c|}
\hline Aboker & Shenkor & Hakim & Dire Teyara \\
\hline $\begin{array}{l}\mathrm{Nl}=19638 \\
\mathrm{nl}=572\end{array}$ & $\begin{array}{l}\mathrm{N} 2=20637 \\
\mathrm{n} 2=601\end{array}$ & $\begin{array}{l}\mathrm{N} 3=26146 \\
\mathrm{n} 3=761\end{array}$ & $\begin{array}{l}\text { N4 }=\mathbf{3 7 3 3 9} \\
\text { n4 }=1087\end{array}$ \\
\hline $\mathrm{nl}=119$ & $\mathrm{n} 2=125$ & $\mathrm{n} 3=159$ & $\mathrm{n} 4=227$ \\
\hline
\end{tabular}

Proportional Allocation to each woreda

From Each woreda, two kebles were selected using SRS proportional Allocation to each kebele

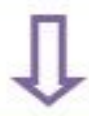

From each kebeles, the required sample were collected via spinning.

\section{Figure 1}

Sampling procedure used for study among elderly peoples in Harar, 2018/2019 (NB: * shows randomly selected woredas for the study using Simple random sampling) 


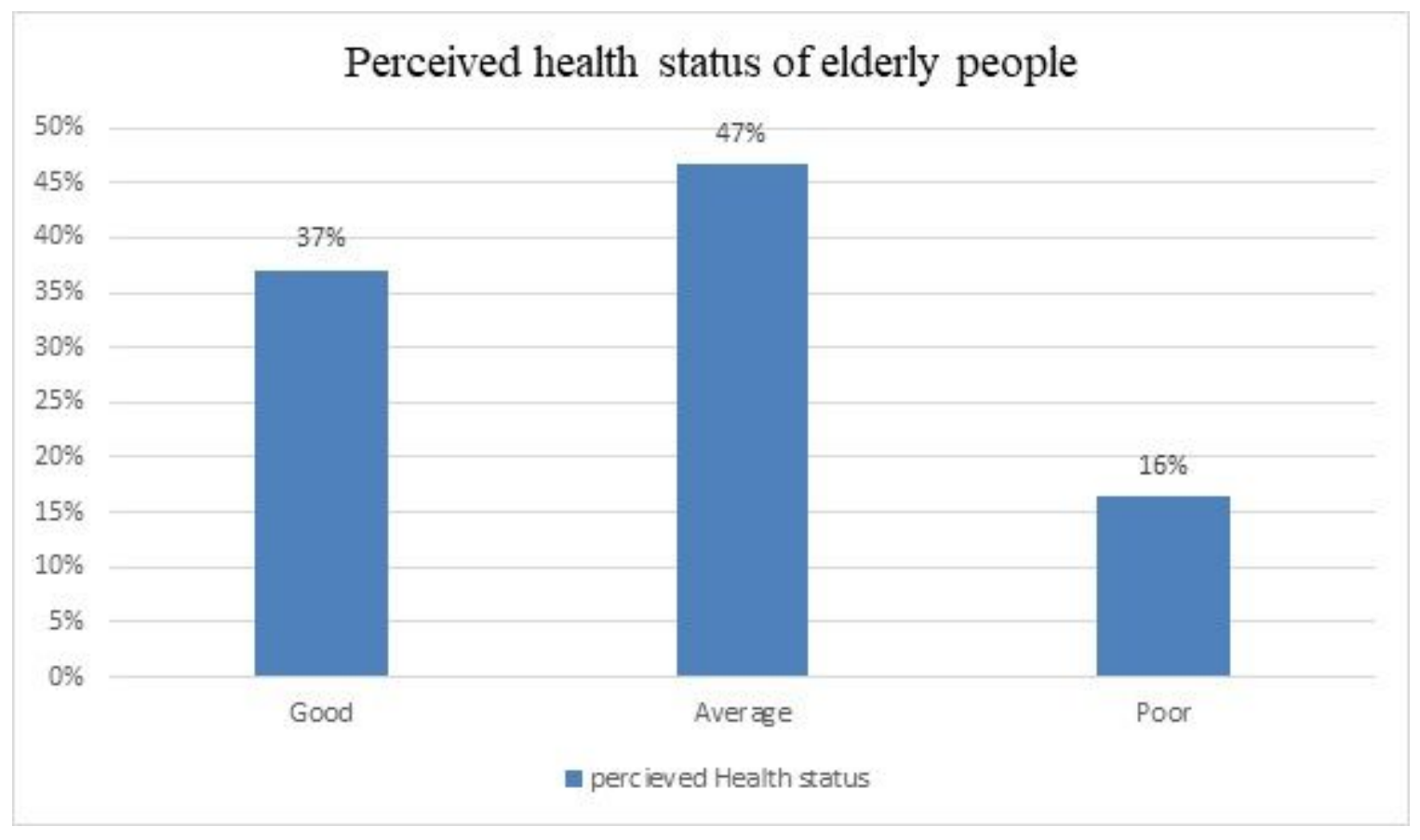

\section{Figure 2}

Perceived personal health status of elderly people aged above 65 years of age in Harari Regional state, Eastern Ethiopia, 2019 (blue shows the percentage)

Level of malntrition among elderly in Percentage

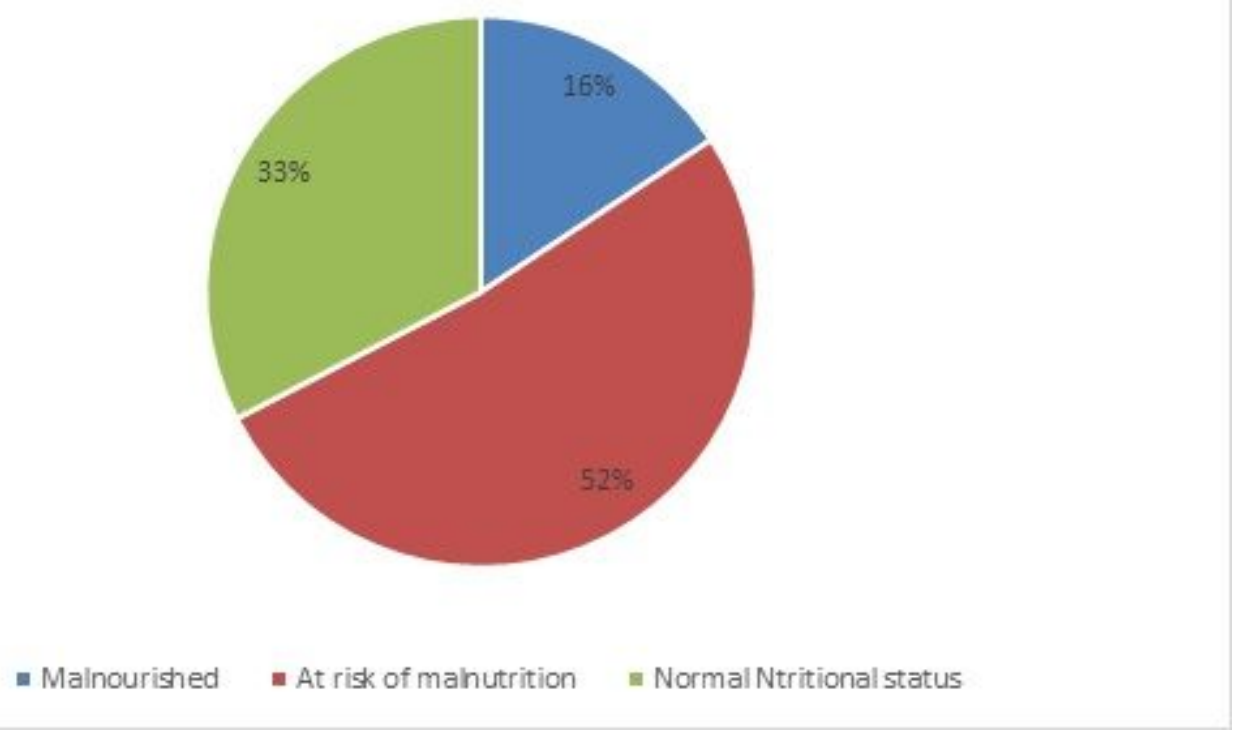

\section{Figure 3}

Nutritional status of elderly people in Harari Region, Eastern Ethiopia $(n=592)$ (Red refers for at risk of malnutrition, blue= malnourished and else as normal)

\section{Supplementary Files}


This is a list of supplementary files associated with this preprint. Click to download.

- Formula1.pdf 